\title{
Findings of the Work Improvement on Board (WIB) programme by the Fishery Agency in Japan
}

\author{
Shuji Hisamune ${ }^{1}$, Kazutaka Kogi ${ }^{2}$ \\ ${ }^{1}$ Faculty of Economic, Takasaki City University of Economics, Takasaki, Gunma, Japan \\ ${ }^{2}$ Institute for Science of Labour, Kawasaki, Kanagawa, Japan
}

\begin{abstract}
Background: Concerns are growing about the safety and health of seamen exposed to high risks while working on vessels. Their accident rate in 2013 was 9.9 per 1000 workers, 5 times higher than that in industry. In order to mitigate the risks of seamen, we developed the Work Improvement on Board (WIB) programme by applying participatory action-oriented training (PAOT) methods that have proven effective for reducing work-related risks in small enterprises, construction sites, and agriculture.

Materials and methods: We analysed which features of the WIB programme would be most effective for facilitating the planning and implementation of practical improvements on vessels. We examined action -oriented tools used, including a WIB action checklist and good examples, and practical improvements proposed by the participants in 1-day or half-day WIB workshops. To study the effectiveness of the WIB programme, we analysed 1121 replies of a questionnaire distributed to 1459 participants of the programme. We compared the types of improvements achieved and the improvement costs in the WIB programme with those in other PAOT programmes. The impact of the WIB programme on promoting primary prevention by seamen and fishermen was discussed.

Results: The action checklist listing practical improvements on board and good example photos apparently facilitated the planning and implementation of improvements feasible on board. The participating crews could propose readily applicable improvements of their vessels within short time. In the case of workshops held in 10 harbours between August and October 2014, participants coming from 110 vessels presented 228 improvement proposals which were mostly feasible at low cost. Among the 1121 questionnaire replies from participants of the WIB programme, over $75 \%$ evaluated the programme as necessary, practical and easy-to-understand. These positive results led to the adoption of the WIB programme for training fishermen and seamen on commercial vessels by the Fishery Agency and the Ministry of Land, Infrastructure, Transport and Tourism. The Fishery Agency adopted plans to improve the working environment on fishing vessels by training 500 fishermen per year in the WIB programme from 2013 to 2018.

Conclusions: The participatory work improvement programme can work in vessels when it utilises in a flexible manner local good practices and low-cost improvements as guides. The use of action-oriented tools such as a WIB action checklist and good examples seems important. We recommend the wide use of WIB methods in occupational safety and health management systems on board vessels in Japan and other countries.
\end{abstract}

(Int Marit Health 2015; 66, 3: 152-159)

Key words: occupational safety and health, seamen, work improvement, participatory action-oriented training 


\section{INTRODUCTION}

Concerns are growing about the safety and health of seamen exposed to high risks at work on vessels [1]. In 2013, their accident rate was 13.5 per 1000 workers, 6 times higher than that in industry. Meanwhile, the death rate of seamen from accidents in 2014 was 0.2 per 1000 workers, 5 times higher than that in industry. In order to mitigate the risks of seamen at work [2], we developed the Work Improvement on Board (WIB) programme by applying participatory action-oriented training (PAOT) methods that have been proven effective for reducing work-related risks in small enterprises, construction sites, and agriculture [3]. There are yet a number of the occupational safety and health management systems' (OSHMS) steps that could be simplified and adapted to the size and technical means of the enterprise.

The PAOT training packages represented by work improvement in small enterprises (WISE), the work improvement in neighbourhood development (WIND) for small scale farmers and the POSITIVE programme for trade unions have been developed and tested extensively by the International Labour Organisation and occupational safety and health programmes in many countries [4]. They include simplified forms of risk assessment similar to step 1 of OSHMS implementation. While they are not initiated as an OSHMS model, they are based on basic primary prevention methodologies presented in a simple manner for small-scale workplaces [5]. The effectiveness of these methods is based on the fact that the workers know the high risks and necessary countermeasures based on their own experiences and that the improvements implemented by them focus on ergonomic principles for reducing multifaceted risks at work. The participatory procedures leading to these improvements and the types of ergonomic improvements implemented on vessels are examined to know the necessary support measures useful for widely applying the WIB programme to different groups of seamen and fishermen.

\section{MATERIALS AND METHODS}

We analysed the features of the programme that would be most effective for facilitating the planning and implementation of practical improvements on vessels. The features of training tools used in WIB training sessions, including an action checklist incorporating multifaceted improvement actions, were examined. These tools were applied for facilitating group discussions of participating workers.

By comparing the steps taken in the WIB programme, the training procedures taken in the 1-h or 2-h WIB workshops were then studied. Types of improvements actually applied for improving working conditions of the participating seamen and their relations to ergonomic principles were examined. The costs of the implemented improvements were also analysed. The views of the participants about the WIB programme were studied by means of applying a simple questionnaire filled in by participating seamen and fishermen and analysing 1121 replies of a questionnaire distributed to 1459 participants of the WIB programme at all the workshops conducted by the Fishery Agency during 2013-2014. All the participants from various parts in Japan were male, with the average age 44.6 years.

The impact of the WIB programme was further discussed based on the collaboration with various maritime organisations and relevant government agencies.

\section{RESULTS}

\section{PARTICIPATORY TOOLS USED IN THE WIB PROGRAMME}

The 28 items of the action checklist covered (a) work space and its maintenance, (b) preventing falls, (c) machine safety and protective equipment, (d) lighting, (e) mooring and fishing equipment, (f) work operations, (g) communication and welfare facilities. The typical improvement actions incorporated in the action checklist are shown in Table 1.

The typical types of photo sheets used for WIB training are shown in Figure 1. After the presentation by the trainers about the basic principles of improvement actions, participants checked their vessel by utilising the WIB action checklist. Then the participants discussed the existing good practices and the ideas for work improvements that could be implemented by themselves. At the end of the workshop, participants agreed to propose 3 work improvements for their vessel and workplace.

Many of the proposed improvements were implemented with visible effects on safety and health at work. The participants used a WIB flow sheet in which they wrote down the improvement plans agreed on and the results of actions taken. The simple format of the flow sheet helped workers propose their own improvement actions. An example of the WIB flow sheet filled in by workers of a vessel is shown in Table 2. Typical improvements included better materials handling, safer operation of machines, prevention of falls, regular use of life jackets and protective equipment and improved welfare facilities. An example of the flow sheet for WIB methods in occupational safety and health management systems on board is shown in Table 3.

The combined use of the action checklist, photo sheets and the WIB flow sheet obviously facilitated the required group work to propose potential improvements. The participants could learn practical types of work improvements from the action checklist and photo sheets. They could easily understand the actions feasible in addressing their local needs and could thus propose and implement them by means of the flow sheet. To study the effectiveness of the WIB programme, we analysed 1121 replies of a questionnaire distributed to 1459 participants. 
Table 1. Typical check items in the Work Improvement on Board (WIB) action checklist

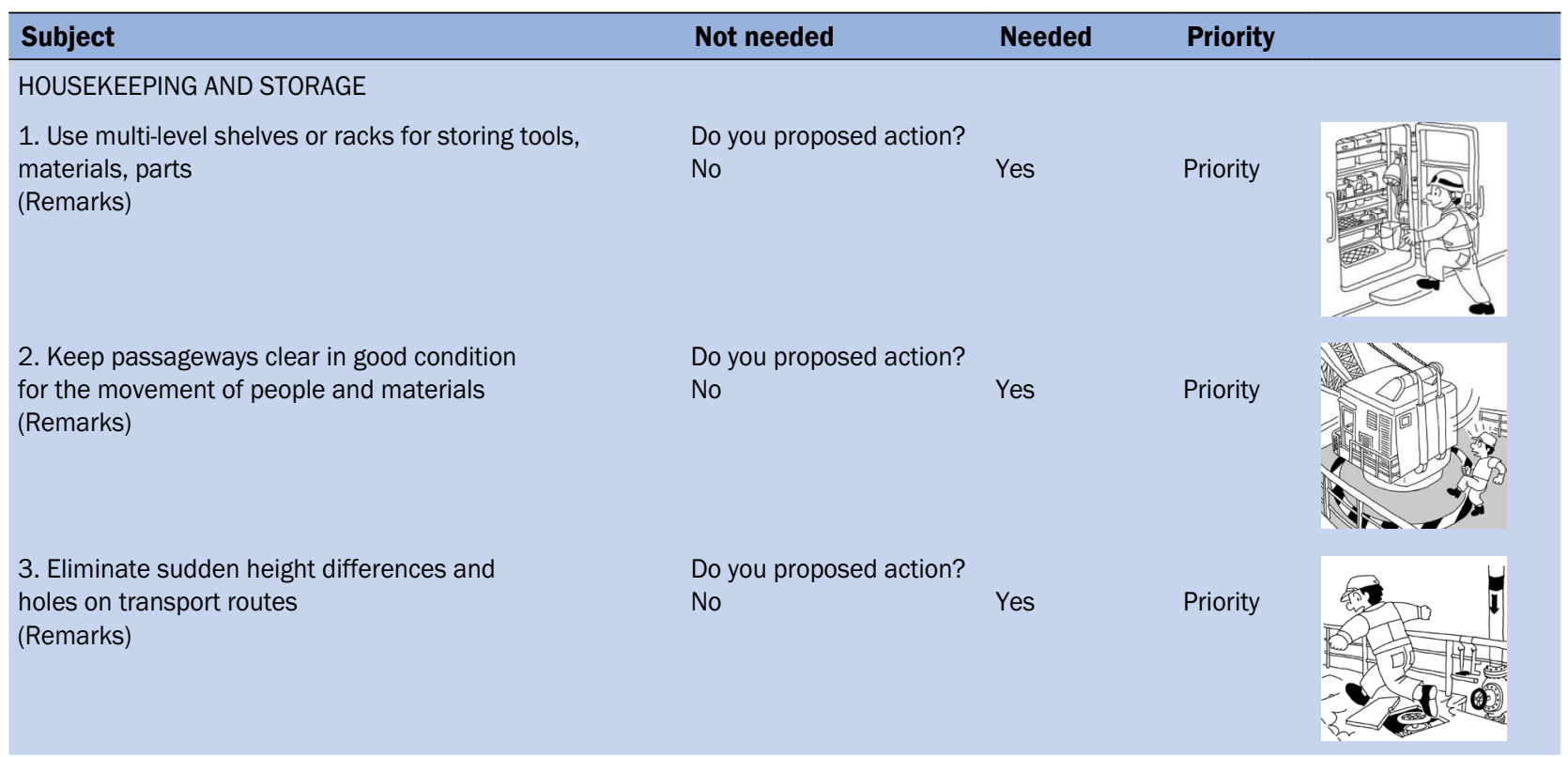

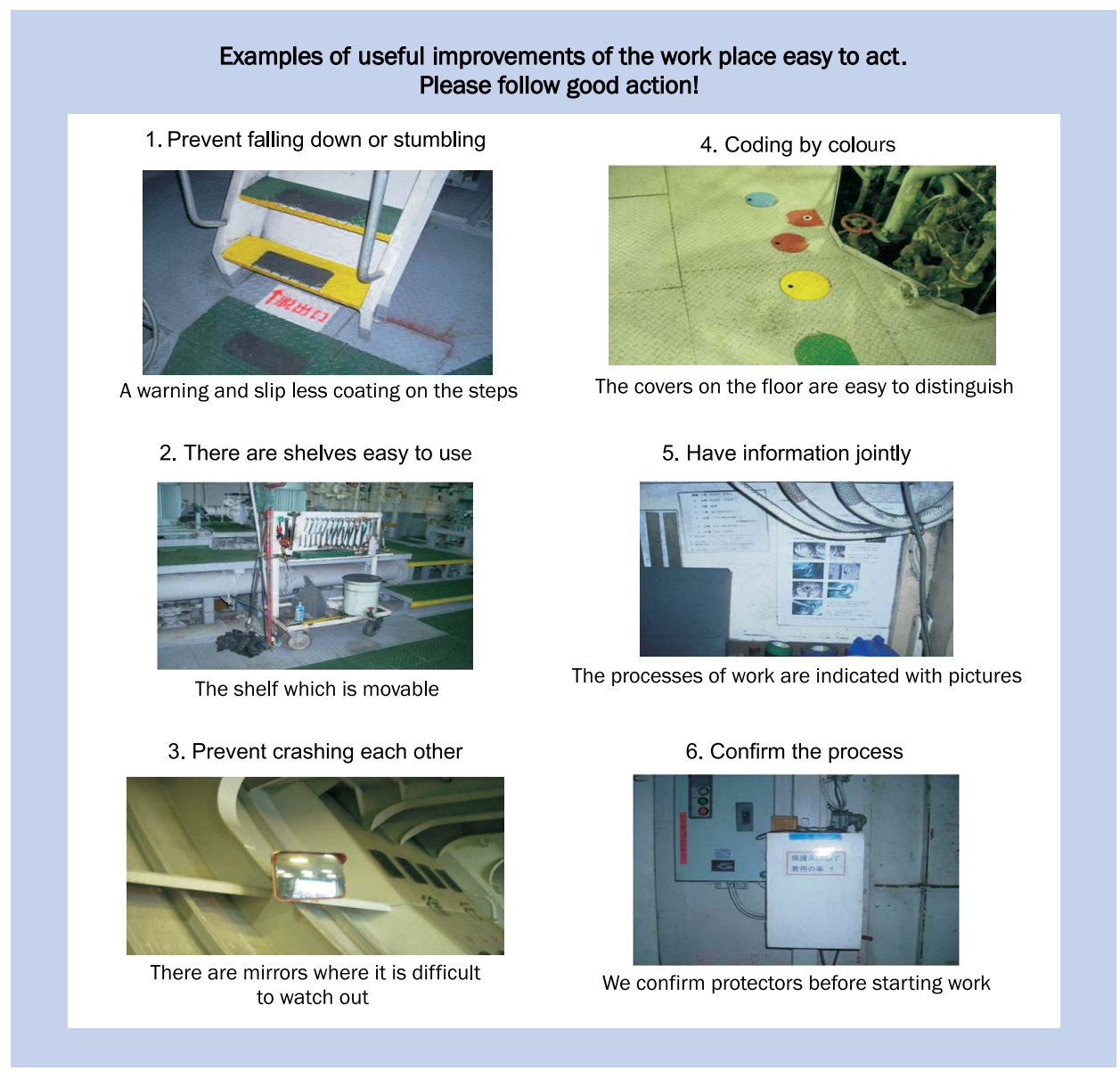

Figure 1. Work Improvement on Board (WIB) photo sheets showing good examples 
Table 2. An example of the Work Improvement on Board (WIB) planning sheet for writing down the improvement plans and the results

\begin{tabular}{|c|c|c|c|c|c|c|}
\hline \multicolumn{2}{|c|}{ Date: 1 June 2014} & \multicolumn{2}{|c|}{ Members: A, B, C } & \multicolumn{3}{|l|}{ Name of vessel: Vessel } \\
\hline \multicolumn{4}{|c|}{ PLAN OF IMPROVEMENTS } & \multicolumn{3}{|l|}{ RESULTS } \\
\hline $\begin{array}{l}\text { Order in } \\
\text { priority }\end{array}$ & Improvement points & Deadline & Costs & Actions taken & Photos & \\
\hline 1 & Providing non-slip mats & End of August & $\begin{array}{l}\text { Paints, non-slip } \\
\text { material }\end{array}$ & Using paints with sand & & \\
\hline 2 & Preventing hitting the head & End of July & $\begin{array}{l}\text { Urethane, black- } \\
\text {-and-yellow tapes }\end{array}$ & $\begin{array}{l}\text { Placing warning signs } \\
\text { at head level }\end{array}$ & & \\
\hline 3 & Making it easy to locate tools & End of June & $\begin{array}{l}\text { Wooden board, } \\
\text { hooks }\end{array}$ & $\begin{array}{l}\text { Placing tools according } \\
\text { to their sizes }\end{array}$ & & \\
\hline
\end{tabular}

Table 3. An example of the flow sheet used in the Work Improvement on Board (WIB) activities so as to indicate their links with the occupational safety and health management systems on board

$\begin{array}{ll}\begin{array}{l}\text { Occupational safety } \\ \text { and health policy } \\ \text { Organisers }\end{array} & \begin{array}{l}\text { President } \\ \text { Manager (Secretariat in the vessel) } \\ \text { Captain (Leader in the vessel) }\end{array} \\ \begin{array}{ll}\text { Planning and } \\ \text { implementation }\end{array} & \begin{array}{l}\text { Planning meeting (.../month/year) } \\ \text { Implementation }(. . . / \text { month/year) }\end{array} \\ \text { Tudit } & \begin{array}{l}\text { Audit meeting }(. . . / \text { month/year) } \\ \text { Implementation }(. . . / \text { month/year) }\end{array} \\ & \text { Training (.../month/year) } \\ \text { Continual } & \\ \text { improvement } & \end{array}$

\section{EVALUATION OF THE WIB WORKSHOP RESULTS}

The evaluation results for the WIB workshops are shown in Figure 2. The majority of the participants found the programme interesting and over $80 \%$ of the replies evaluated the WIB workshop easy-to-understand, effective for making improvements and practical.

When the participants were asked to evaluate the WIB programme as a whole, the results were very positive as shown in Figure 3. Over $80 \%$ of them evaluated the WIB system as a training programme easy-to-follow, necessary tor leading to actual improvements and practical for this purpose.

In the workshop, the participants did not require special knowledge concerning work safety and vessels. The participating crews could propose readily applicable improvements of their vessels within short time. In the case of workshops held in 10 harbours between August and October 2014, participants coming from 110 vessels presented 228 proposals for improving their own conditions. The contents of these 228 proposals were classified as shown in Figure 4 that compared them with the distribution of accident reports from fishing boats and from merchant vessels. It was clear that the participants concentrated on improving work methods and the usage of equipment.

We classified responses into 5 categories: (1) improve the method of work; (2) improve equipment; (3) improve education; (4) confirm safety; and (5) call attention to. The second category, "improve equipment", accounted for $75 \%$ of suggestions. We compared this with the WIB workshop and reports of crew accidents and saw that measures for work accidents included written reports of cases of illness and accident; these written reports of crew accidents were handed in to the Ministry of Land, Infrastructure, Transport and Tourism from 4 April 2002 to 31 March 2003. In this report, we investigated 504 cases for which there 


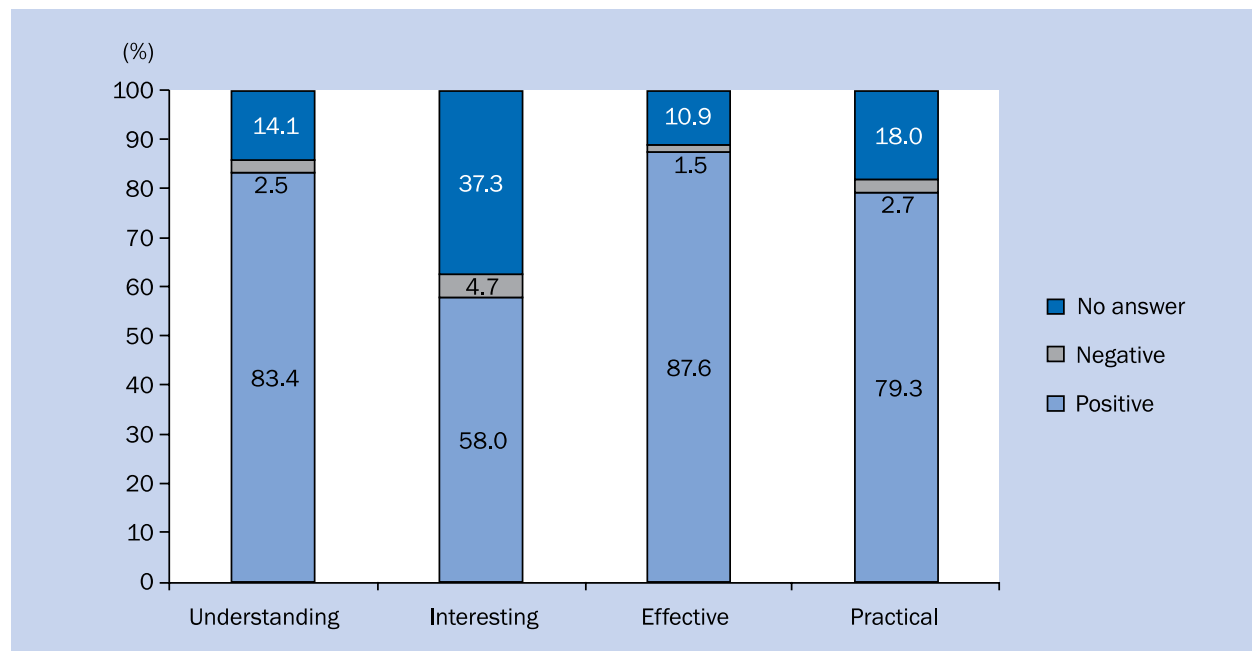

Figure 2. Evaluation of the Work Improvement on Board (WIB) workshop by the questionnaire distributed to participating fishermen $(n=1121)$

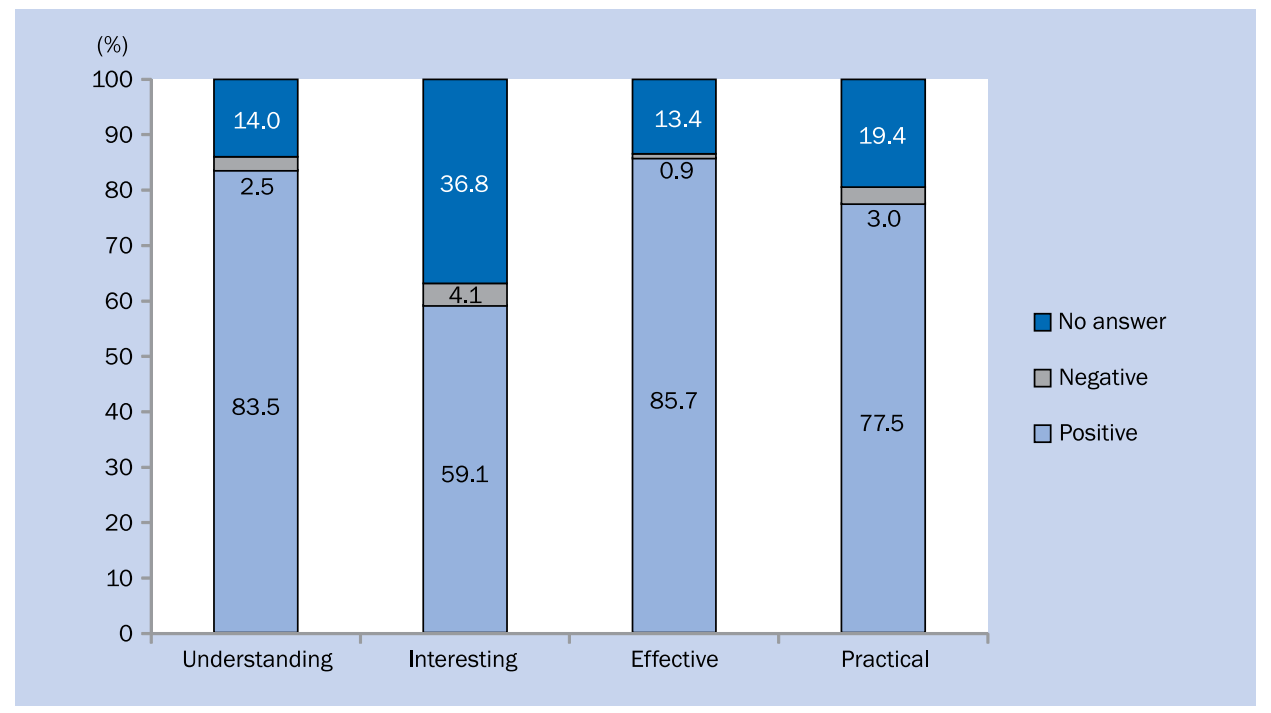

Figure 3. Evaluation of the Work Improvement on Board (WIB) system by the questionnaire distributed to participating fishermen $(n=1121)$

were written details of the work accident. The majority of these cases tended to be reported as related to the need for education or for promoting individual workers' "checking safety" and "calling attention". By participating in the WIB programme, in contrast, the participants could learn to more closely look at collective work procedures and equipment $(p=0.01)$. This may imply that the WIB programme is more effective for preventing accidents than the way seamen used to do.

\section{DISCUSSION}

When the improvements implemented by the participants of the WIB programme were classified according to their technical areas, they covered major technical areas considered important from ergonomic points of view. The distribution of the implemented improvements according to technical areas is shown in Figure 5. Compared with corresponding results from WISE and WIND programmes [3, 4], the results from the WIB programme were similar to those from the WIND and WISE programmes. About $40 \%$ of the improvements by the WIB programme were about "materials handling" accounted for $13.3 \%$, "machine safety" $37.3 \%$, "work environment" $41.3 \%$ and "welfare facilities" $8.0 \%$. The participants of the WIB programme were thus guided to sufficiently look at ergonomic aspects of work with the help of the action checklist and photo sheets. 


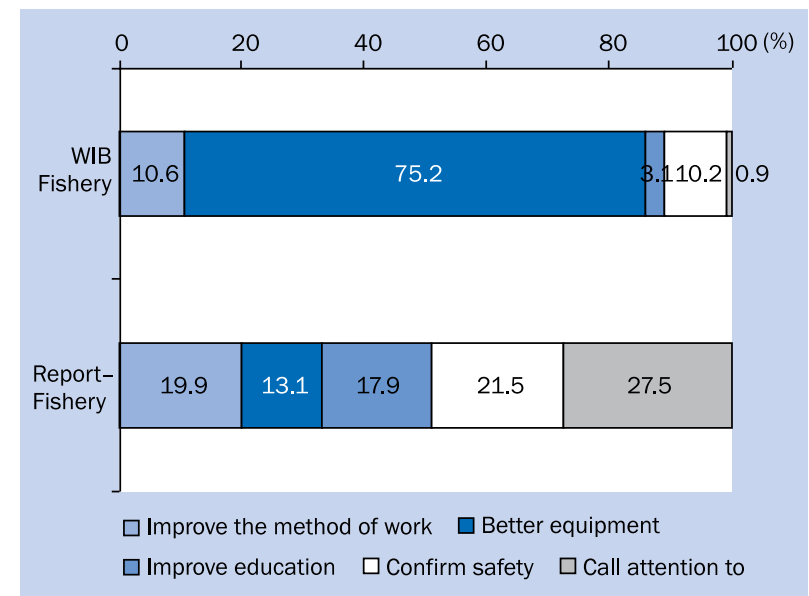

Figure 4. Classification of work improvements as accident measures. Note: The five cost categories: (1) Improve the method of work; (2) Improve equipment; (3) Improve education; (4) Confirm safety; and (5) Call attention to; $F=$ test $(p=0.01)$

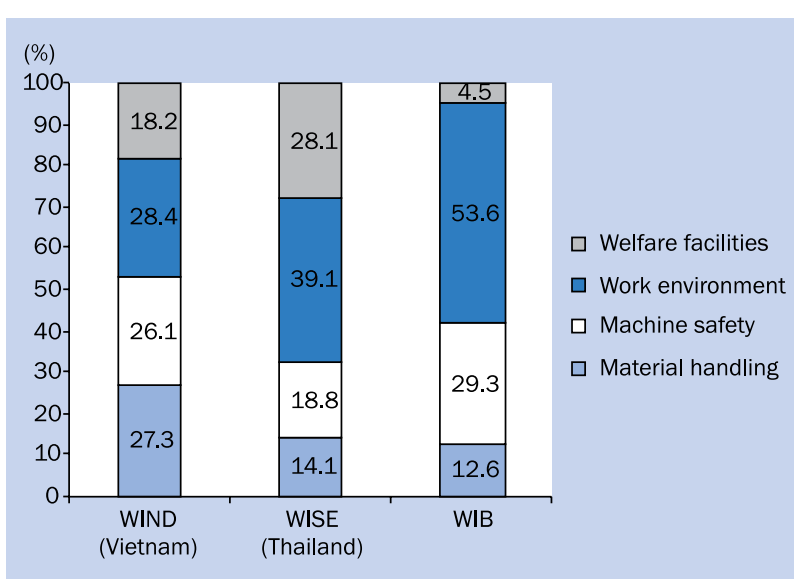

Figure 5. Classification of the technical areas of work improvements implemented. Note: The four cost categories: "materials handling", "machine safety", "work environment", "welfare facilities"

Further, the merits of aiming at low-cost solutions are notable in the WIB programme as in the case of WIND and WISE programmes. The actual costs needed for implementing the work improvements are compared among these programmes as shown in Figure 6. The costs of improvements done were classified into 3 categories: "zero", "inexpensive" (less than US\$ 10 in WIND, less than US\$ 20 in WISE and less than US\$ 100 in WIB) and "relatively costly" (US\$ 10 or more in WIND, US $\$ 20$ or more in WISE and US\$ 100 or more in WIB). In the case of the WIB programme, the improvements at "zero" cost accounted for $33.3 \%$, "inexpensive" for $34.7 \%$, and "relatively costly" for $32.0 \%[3,6]$. The pattern of the cost distribution was similar to that in the case of WIND or WISE. The low-cost nature of the improvements implemented

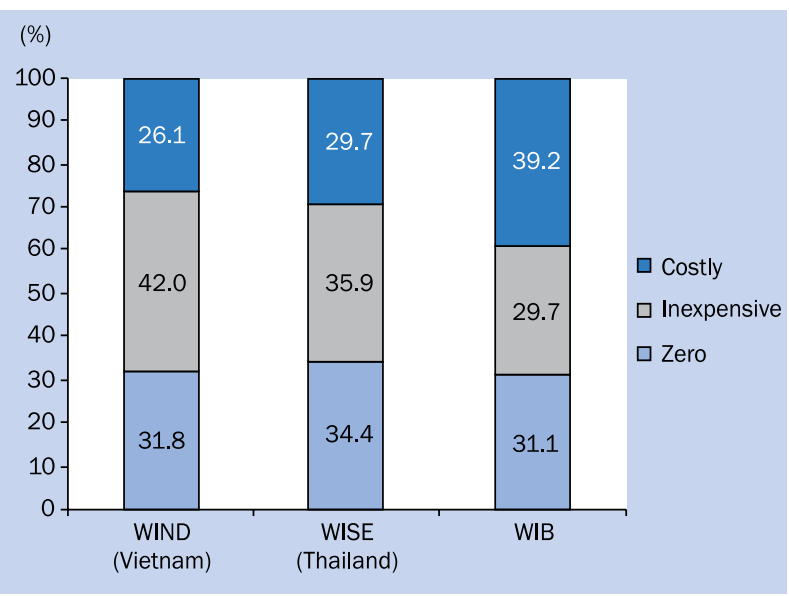

Figure 6. Distribution of the costs needed for implementing the proposed work improvements. Note: The three cost categories: for Work Improvement on Board (WIB) "zero", "Inexpensive" is "less than US\$100" and "Costly" is "US\$100 or more"; for WISE (Thailand) "zero", "Inexpensive" is "less than US\$20" and "Costly" is "US\$ 20 or more"; for WIND (Vietnam) "zero", "Inexpensive" is "less than US\$10" and "Costly" is "US\$ 10 or more"

by these programmes is proven by this comparison. The prevalence of low-cost improvements in implementing each programme may thus explain the background reason for the success of participatory approaches in all these small-scale workplaces.

Examples of improvements achieved by the WIB programme are shown in Figure 7. For example, the deck light was changed to the LED light on a shell fishing boat in Aomori Prefecture. The cost was about US\$400. The electric power by the LED light reduced to $266 \mathrm{~W}$ per hour and save US $\$ 250$ per year. The fishermen could work more safely on the deck. Next, the scallop washing machine is noisy the worker could not hear another worker's voice. When the mirror put on the ceiling, the worker could confirm another worker's behaviour. In the participatory, action-oriented training workshops carried out, the participating workers and managers were able to identify their priority safety and health actions. This was consistent with our previous intervention experiences in vessels that were similar to those in small enterprises and agriculture.

The WIB programme conducted for seamen and fishermen led to numerous improvements in participating vessels in different parts of Japan. The WIB workshops facilitated the planning and implementation of low-cost improvements with concrete results. The implemented improvements could actually reduce the accident risks and contributed to improved workplace conditions on vessels. The effectiveness of the WIB programme could be verified by the wide coverage of improvements achieved and the evaluation by the participants. 


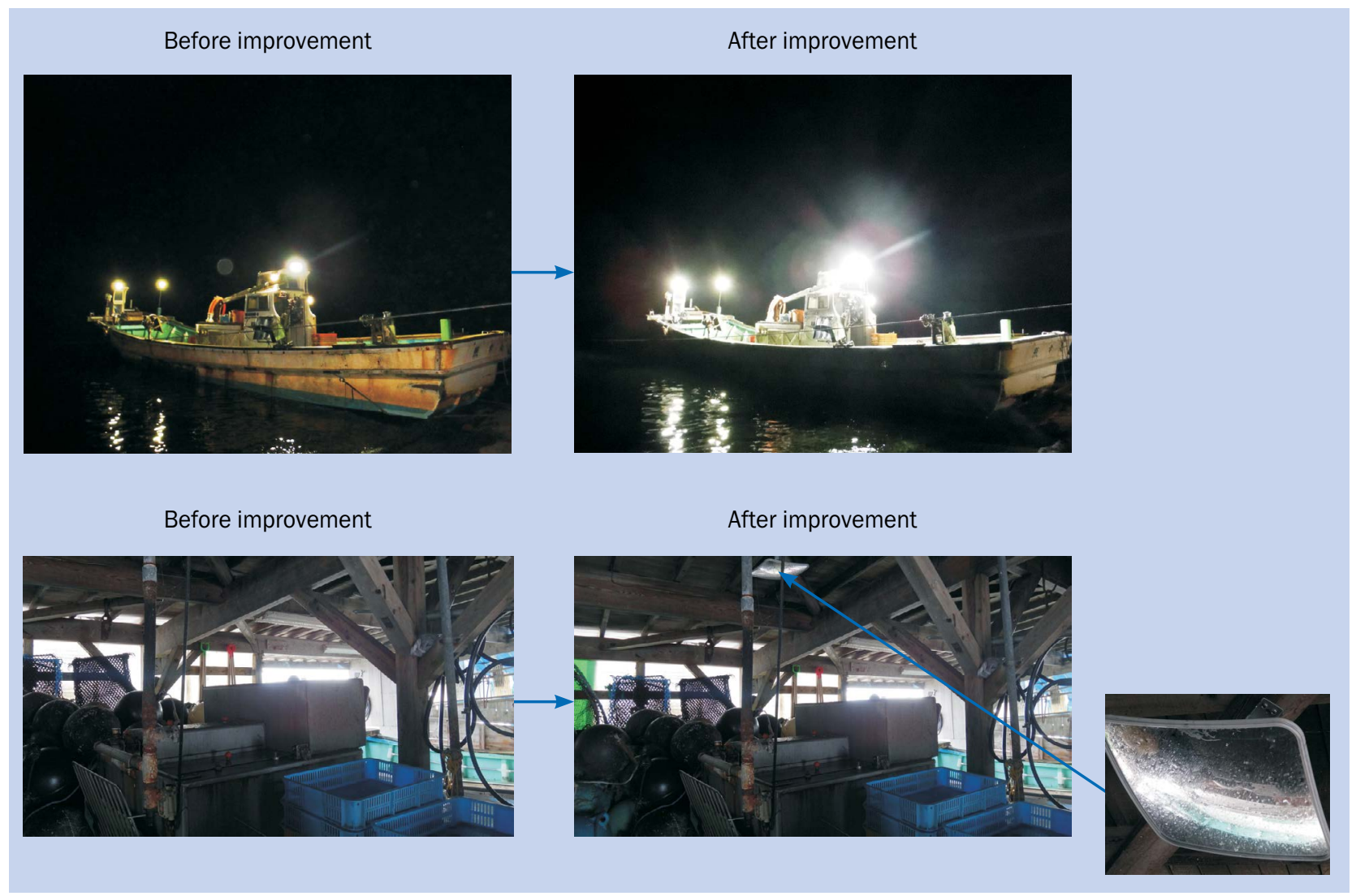

Figure 7. Examples of improvements achieved by the Work Improvement on Board (WIB) programme

This led to the adoption of the WIB programme for training seamen and fishermen by the Fishery Agency and the Ministry of Land, Infrastructure, Transport and Tourism. The Fishery Agency adopted the plans to improve fishery working environment by training 500 fishermen per year by the WIB programme during 2013-2018. Over 1500 fishermen have been trained by the WIB programme during 2013-2014. This is realised by utilizing the fishery association network.

The support tools such as action checklists, good examples and implementation guides have proven useful in facilitating the planning and implementation of the feasible improvements and confirming benefits in terms of both better safety and health and higher productivity. The interactive group work can lead to multiple improvements in many fishery companies.

The improvement process by applying the WIB programme is greatly facilitated by aiming at spreading local good practices. The participatory steps of the WIB programme and relevant participatory programmes commonly rely on learning-by-doing of good practices locally achieved. These steps have led to many concrete improvements in multiple technical areas covering materials handling, workstations, physical environment and work organisation, all of which are based on ergonomic principles. It is important that most of these improvements have been achieved at low cost. We can confirm that basic participatory steps in securing active participation of local people are similar among the participatory programmes including WIB, WISE and WIND. Learning from the networking arrangements that have contributed to the spread use of WISE and WIND programmes in many countries, It appears necessary to develop similar networking of core and local trainers trained in the use of WIB methods for promoting the wide use of the WIB programme [7].

The locally adjusted procedures of organising a WIB workshop merit our special attention. Usually, local good examples of workplace improvements are collected and used as guidance for learning available good practices. The gained knowledge is utilised by local people for discussing potential options and proposing practical vessel improvements. In this respect, it is necessary to locally adapt the participatory tools, such as an action checklist and photo sheets as well as presentation slides, so as to reflect local situations.

\section{CONCLUSIONS}

The participatory work improvement programmes can work in vessels when they utilise in a flexible manner local good practices and low-cost improvements as guides. The combined use of an ergonomic action checklist and illustrated good examples focusing on low-cost actions has proven effective. The wide applicability of the WIB programme is recognised and its use is supported by the Japan Fishers 
cooperative (JF), Seamen's union in Japan, Japan Coast Guard, and Labour Standards Inspection Office of Ministry of Health, Labour and Welfare. The approach of OSHMS has become popular. The ways for promoting its application vary from legal requirements to voluntary use. It is encouraging that the Tenth Work Accidents Prevention Master Plan of the Ministry included the promotion of the training of WIB trainers obtaining national certification. Experience shows that OSHMS is a logical and useful tool for the promotion of continual improvement of OSH performance at the organisation's level.

We recommend the wide use of WIB methods in occupational safety and health management systems on board in Japan and other countries.

\section{ACKNOWLEDGEMENTS}

The authors express thanks to all those workers and managers who participated in the WIB programme.

\section{REFERENCES}

1. Hisamune S, Amagai K, Kimura N, Kishida K. A study of factors relating to work accidents among seamen. Industrial Health 2006; 44: 144-149.

2. The Ministry of Land, Infrastructure, Transport and Tourism, 2015. The reports of crew accidents. http: http: mlit.go.jp/common/001011531.pdf.

3. Kogi K. Advances in participatory occupational health aimed at good practices in small enterprises and informal sector. Industrial Health 2006; 44: 31-34.

4. Kogi K. Practical ways to facilitate ergonomics improvements in occupational health practice. Human Factors 2012; 54: 890-900.

5. http://www.ilo.org/wcmsp5/groups/public/_ed_protect/-protrav/-safework/documents/publication/wcms_153930.pdf.

6. Ito A, Sakai K, Kogi K. Development of Interactive Workplace Improvement Programs in Collaboration with Trade Associations of Small-Scale Industries. Industrial Health 2006; 44: 83-86.

7. Kawakami T. Networking grassroots efforts to improve safety and health in informal economy workplaces in Asia. Industrial Health 2006; 44: 144-149. 